\title{
Effect of fiber treatment on mechanical properties of kenaf fiber-ecoflex composites
}

\begin{abstract}
The composite material based on whole stem kenaf fiber (WSK) and Ecoflex (biodegradable thermoplastic) were prepared by melt blending technique and characterized. The composites were prepared using different fiber loadings and the fiber was treated with various concentrations of $\mathrm{NaOH}$ solution by soaking for $3 \mathrm{~h}$. The compounding of composite were carried out at different fiber loadings $(10 \%, 20 \%, 30 \%, 40 \%, 50 \%)$ using Brabender internal mixer at $130^{\circ} \mathrm{C}$ for $10 \mathrm{~min}$. The composites were then pressed using compression molding to produce biodegradable kenaf/Ecoflex sheets. The effects of kenaf fiber loading and $\mathrm{NaOH}$ treatment of WSK fiber surface on mechanical properties was examined. The results showed that $40 \%$ fiber loading improved the tensile strength properties and WSK fiber treated with $4 \% \mathrm{NaOH}$ was found to enhance tensile and flexural properties compared with untreated fiber. The FTIR characterization showed that alkali treatment removes hemicellulose and lignin from WSK kenaf fiber surface.
\end{abstract}

Keyword: Whole stem kenaf fiber; Ecoflex biodegradable composites; $\mathrm{NaOH}$ treatment; Mechanical properties 